\title{
Formulation of Hedera helix L. in Topical Dosage Forms: In Vitro and Ex Vivo Evaluation
}

\author{
Rahman Gull,2*, Syed Umer Jan¹, Mahmood Ahmad³, and Muhammad Mukhtiar ${ }^{4}$ \\ ${ }^{1}$ Faculty of Pharmacy and Health Sciences, University of Balochistan, Quetta, Pakistan \\ ${ }^{2}$ Department of Health, Government of Balochistan, Pakistan \\ ${ }^{3}$ Faculty of Pharmacy and Alternative Medicine, The Islamia University of Bahawalpur, Punjab, Pakistan \\ ${ }^{4}$ Department of Pharmacy, University of Poonch, Rawalakot, Azad Jammu and Kashmir, Pakistan
}

\section{ABSTRACT}

e-mail: gul.dotani@yahoo.com

Hedera helix L. is traditional herbal medicine used in the treatment of asthma. The main objective of this study was to formulate a microemulsion, a gel, and an ointment containing the ethanol extracts of $H$. helix $\mathrm{L}$. and to evaluate in vitro and ex vivo permeation. Thin-layer chromatography (TLC) and high-performance liquid chromatography (HPLC) were used to identify and quantify hederacoside $C$ at $210 \mathrm{~nm}$. Evaluation of release and permeation was done by Franz diffusion cells, dialysis cellulose membrane, and natural rabbit skin. Using dialysis cellulose membrane and rabbit skin, various parameters such as permeation coefficient, flux $(J)$, and release kinetics were analyzed with different kinetics models. In the three formulations, release behavior of the microemulsion and gel were similar, but the ointment showed slow release. Maximum amount of drug released from the microemulsion, gel, and ointment formulations through the dialysis membrane was $70.239 \%, 63.9157 \%$, and $40.9154 \%$, respectively. Release via rabbit skin was $66.051 \%$, 59.5\%, and $37.64 \%$, respectively. According to the Korsmeyer-Peppas kinetic model, the microemulsion, gel, and ointment formulations contained $99.10 \%, 98.23 \%$, and $97.45 \%$ of the medicine, respectively. This study demonstrates that in vitro and ex vivo diffusion cell experiments can be utilized to develop formulations of herbal medicines.

KEYWORDS: Hedera helix, hederacoside C, topical formulations, dialysis membrane, rabbit skin, release kinetics

\section{INTRODUCTION}

I edera helix L., commonly known as English ivy or ivy, belongs to the Araliaceae family. Alcohol extraction of $H$. helix has been used since the 19th century in traditional herbal medicine for the treatment of respiratory problems because of its bronchospasmolytic and expectorant effects (1). Utilization of $H$. helix was standardized by a commissioned monograph of the German regulatory authority in 1988, and different formulations of $H$. helix extract-containing medicinal products, such as drops, syrups, tablets sachet, and suppositories, are available $(1,2)$. These formulations can be used in the management of cough, common cold, and symptomatic treatment of acute and chronic inflammatory bronchial disorders (3). Many species of $H$. helix are found in Balochistan, Pakistan.

The biologically active components of medicinal importance are triterpenoids saponins, hederacoside $(B$, $C, F, G, H$, and F) and $\alpha$-hederine (monodesmoside), which are isolated from $H$. helix and are responsible for its $\beta 2$ adrenergic effects, which leads to the bronchodilatory, spasmolytic, mucolytic, and expectorant action (1, 4). Thus, in European Pharmacopoeia, the identification and quantification of hederacoside $\mathrm{C}$ was done by thin-layer chromatography (TLC) and high-performance liquid chromatography (HPLC) (5). In folk medicine, $H$. helix is used for rheumatism, gout, and parasites. In homeopathic medicine, $H$. helix is used in the treatment of respiratory infection $(6,7)$. Topically, the extract of $H$. helix is used in the treatment of cellulite (liprosclerosis) and weight loss (8). Emollient and itch relieving, $H$. helix extract is also used in lotions, creams, and shampoos $(6,9)$. Both barriers and leaves are used in herbal formulations. The extracted hedera saponins are used as an expectorant to treat catarrh and antifungal treatment (10).

The objective of this study was to formulate three topical dosage forms, a microemulsion, a gel, and an ointment, using $H$. helix extracts and to evaluate the release and permeation from topical preparation using Franz cells, dialysis cellulose membrane, and natural rabbit skin.

\section{MATERIALS AND METHODS \\ Chemicals}

Hederacoside $\mathrm{C}$ was purchased as the analytical standard from Sigma-Aldrich (St. Louis, MO, USA). Carbopol P934 was a gift from Merck Sereno (Quetta, Pakistan). Oleic acid was purchased from Merck (Darmstadt, Germany). Hard paraffin, wool fat, cetostearyl alcohol, 
methanol, acetonitrile, disodium hydrogen phosphate, triethanolamine, potassium dihydrogen phosphate, and ethanol (95\%) were also purchased from Sigma-Aldrich. Polysorbate 80 and glacial acetic acid were purchased from Fisher Scientific (Hampton, NH, USA). Cuprophan dialysis cellulose membrane (hydrophilic $128 \times 345 \mathrm{~mm}$ ) was obtained from Medicell Membranes Ltd. (London, England). All other chemicals used were of high purity grade.

\section{Plant Collection and Extraction from Hedera Helix L.}

The leaves of $H$. helix were collected from Quetta, Balochistan between August and September 2015. The plant was identified by a taxonomist (Dr. Rasool Bakhsh Tareen, University of Balochistan).

The extraction was done according to Harborne. Dried plant material (60 g) from $H$. helix was mechanically ground and weighed in a brown glass bottle and added to $900 \mathrm{~mL}$ of $30 \%$ ethanol water and stored for seven days at room temperature. The bottle was shaken after 24 hours occasionally and then filtered. The filtrate was put in the rotary evaporator to reduce the pressure until a thick residue formed. This residue was washed in the separating funnels with ethyl ether to remove the fatty materials and chlorophyll. This procedure was continued with ethyl ether until no colored matter was present. A thick viscous residue obtained was re-dissolved in 200$\mathrm{mL}$ methanol and ethyl ether was added. A yellowishwhite saponin extract formed. Addition of ethyl ether was continued until no more saponin formed. The saponin was obtained by decantation and air-dried at room temperature, yielding the extract $(7.0 \mathrm{~g})$.

\section{Isolation and Isolation and Identification by Thin-Layer Chromatography (TLC)}

To identify the necessary component of $H$. helix extract, three different developing solvents were used as the mobile phase using a prepared glass and aluminum plate of silica gel $(20 \times 20 \mathrm{~cm}, \mathrm{GF} 254)$ as the coating substance.

- Methanol: chloroform: water (50:40:10)

- Methanol: glacial acetic acid: chloroform: water (30:10:50:10)

- $\quad \mathrm{N}$-butanol: water: glacial acetic acid (940:50:10)

The best separation of the active marker of hederacoside $C$ in the chromatogram was fully identified at 254 and 365 $\mathrm{nm}$. Each zone was scrapped, isolated, and dissolved in ether, which gave the desired compounds after filtration and removal of the solvent. The identification was also done by comparing $\mathrm{Rf}$ values for the standard and plant extract under the same conditions.

\section{Quantification of Hederacoside C from $H$. helix Extract by HPLC}

The high-performance liquid chromatography (HPLC) method was performed using an Agilent 1100 HPLC system (Agilent Technologies, Santa Clara, CA, USA) equipped with manual injector system, Shimadzu (Kyoto, Japan) LC-10ATvp pump, DGU-14A degasser, and SPD-10A VP UV-VIS detector, and Hypersil ODS C8 (150 x $4.6 \mathrm{~mm})$ column (Thermo Scientific, Waltham, MA, USA). Agilent ChemStation software was used for data collection and processing. The chromatographic conditions used for analysis were as follows. The mobile phase consisted of acetonitrile, water, and orthophosphoric acid (150:850:2). The flow rate was $1.0 \mathrm{~mL} / \mathrm{min}$, injected volume was 20 $\mu \mathrm{L}$, and samples were detected by an ultraviolet-visible detector at a wavelength of $210 \mathrm{~nm}$. The retention time of hederacoside $C$ was 9.6 and 10.0 min.

\section{Preparation of Microemulsion}

Preparation of microemulsion was done according to Chen et al. (12). A polysorbate 80 mixture of a surfactant and ethanol (co-surfactant) in a 2:1 ratio was mixed vigorously. A 4.6-g sample of the surfactant mixture was added to the oil (oleic acid, $0.5 \mathrm{~g}$ ) and mixed together along with plant extract $(0.5 \mathrm{~g})$ using a magnetic stirrer. Distilled water (4.4 g) was slowly added under continuous stirring $(1200 \mathrm{rpm})$ at room temperature $(13,14)$.

\section{Preparation of Gel}

The gel was prepared according to Proniuk et al (15). Carbopol 934p (1 g) was weighed and dissolved slowly in distilled water while stirring continuously (1200 rpm) at ambient temperature to form a $1 \%$ solution. Triethanol amine was added slowly drop-wise to the prepared gel to increase the $\mathrm{pH}$ to 5.7. Then, we added plant extract ( $5 \mathrm{~g}$ ) and measured the characterization $(13,14)$.

\section{Preparation of Ointment}

Formulation of the simple ointment B.P. was done according to Marriot et al. by first melting the hard paraffin $(4.75 \mathrm{~g})$ at $60^{\circ} \mathrm{C}$ then adding wool fat $(4.75 \mathrm{~g})$ followed by cetostearyl alcohol (4.75 g) (16). The mixture was stirred and cooled at ambient temperature. Soft white paraffin $(80.75 \mathrm{~g})$ and plant extract $(5.0 \mathrm{~g})$ was added and the characterization was measured. $(13,14)$.

\section{Analysis of Drug Content}

Drug content of all formulations was analyzed. A 10$\mathrm{mg}$ sample was weighed and added to $100 \mathrm{~mL}$ of hydroalcoholic solvent in a conical flask and stirred with a 
magnetic stirrer for 1 hour until dissolved completely. The dissolved solution was filtered through a membranous filter $(0.2 \mu \mathrm{m})$ and assessed by a validated HPLC method, and the drug concentration was calculated.

\section{Preparation of Rabbit Skin for Franz Diffusion Cells}

Albino rabbit skin was used for ex vivo permeation studies of the plant extract. The rabbit was anesthetized with chloroform and hair was carefully shaved from the dorsal region with an electric razor. The skin was washed with a cotton swab. We waited 24 hours so that the skin would become normal. The rabbits were scarified, and the skin was excised carefully with the help of sharp blade. The epidermis was removed by dipping it in hot water of almost $600^{\circ} \mathrm{C}$. The dermis was teased from the other two layers and the layers were separated. The epidermis layer was cleaned with distilled water, covered with aluminum foil, and stored at $-500{ }^{\circ} \mathrm{C}$ until further use $(14,17)$.

\section{Franz Diffusion Cell Setup and Receptor Media Prepa- ration}

A Franz diffusion cell apparatus (PermeGear, Hellertown, PA, USA) was used for in vitro and ex vivo studies of $H$. helix extract. The solution used in the receptor is called receptor medium. It is selected based on its physical and chemical compatibility with the artificial and natural membrane, drug, and formulations. Because semi-solid dosage forms from plant extracts were used in this study, the receptor media was composed of ethyl alcohol and phosphate buffer (25:75). The medium was filtered through a $0.2-\mu \mathrm{m}$ membrane, and the temperature of the medium was maintained at $32{ }^{\circ} \mathrm{C}$ in a circulating temperature-controlled bath set to $32.5{ }^{\circ} \mathrm{C}$. Franz diffusion cells should be free from air bubbles. The system was allowed to settle for 30 minutes before use (18-21).

\section{Application of Sample to Artificial Membrane and Prepared Rabbit Skin}

The dialysis cellulose membrane and natural rabbit skin were cut in equal sizes to fit the diameter of the orifice of the Franz cell and were positioned over the open end of receptor section so that the dialysis membrane or rabbit skin covered the open end of the cell completely. A 1-g sample of the formulation was added via syringe to the membrane or skin. The sample was positioned so that it attached to the membrane and the donor compartment was positioned over the receptor compartment. The stainless-steel clamp was used to bring the compartments together and connect the assembly. Further, the complete assembly was put on the magnetic stirrer and receptor fluid was allowed to stir constantly at a speed of $600 \mathrm{rpm}$ using magnetic bars.

\section{Sampling}

From each Franz diffusion cell, 1-mL samples were drawn using a 1-mL syringe through the sampling point. At the time of sampling, stirring was stopped and the sample was taken and stirring continued afterwards with fresh medium. Throughout the sampling process, we ensured that there were no bubbles in the receptor medium or in the syringe because trapped air decreases the volume and area available for permeation. If bubbles appear in receptors compartments, it can be detached by gently tilting the Franz cells. The sampling intervals were at 0.5 , $1,2,3,4,5,6,12$, and 24 hours, and recovered samples were analyzed by HPLC (22-24). To accommodate slight variations in the six Franz cells, experiments were performed in triplicates.

\section{Pharmacokinetic Studies of hederacoside C across the Rabbit Skin}

The quantity of drug in the receptor medium was analyzed ( $0-24 \mathrm{~h}$ ) by HPLC, and the released amount of drug was identified and computed. Linear regression analyses and parameters of drug permeation for each formula were analyzed. The correlation coefficient $\left(R^{2}\right)$ was calculated for each formula by each kinetic equation to assess whether the permeation of the drug through the membrane or natural skin follows a zero order, first order, Higuchi, Korsmeyer-Peppas, or Hixon-Crowell diffusion release model. All calculations were carried out according to the following kinetics equations using DDSolver (a Microsoft Excel 2007 add-in program) (25). All calculations were performed according to the following Equations 1-5.

Zero-order model:

$$
A=K_{0} t+A_{0}
$$

where $A$ is the amount of drug released at time $t$ and $K_{0}$ is the zero-order release rate constant.

First-order model:

$$
\log A=K t / 2.3+\log A_{0}
$$

where $A_{0}$ is the amount of drug release at time $t$ and $K$ is the first-order rate constant.

Higuchi-diffusion model

$$
\mathrm{Q}=\mathrm{K}_{\mathrm{H}} \mathrm{t}^{1 / 2}
$$

where $Q$ is the amount of drug released to the membrane (in $\mathrm{mg}$ ) at time ( $\mathrm{t}$ ) in minutes. $\mathrm{K}_{\mathrm{H}}$ is the Higuchi square root of time release constant. 
Korsmeyer-Peppas model

$$
\mathrm{C}_{\mathrm{t}} / \mathrm{C}_{\infty}=\mathrm{Kt}^{\mathrm{n}}
$$

where $C_{t} / C_{\infty}$ is a fraction of drug released at time $t, K$ is the release constant, and $\mathrm{n}$ is the release exponent.

Hixson-Crowell diffusion release model

$$
\mathrm{Q}_{\mathrm{t}} / \mathrm{Q}=\mathrm{K} \mathrm{t}^{\mathrm{n}}
$$

where $Q_{t} / Q$ is the amount of released drug at time $t, K$ is the constant comprising the structural and geometric characteristics of the formulations, and $\mathrm{n}$ is the release of exponent.

\section{Statistical Analysis}

Two-way multivariate analysis (ANOVA) was used to evaluate the effect of dialysis cellulose membrane and natural rabbit skin using SPSS (version 18.0, IBM, Armonk, NY, USA) (26). For comparison of the formulations, the similarity factor $\left(f_{2}\right)$ analysis was used (27). The data from all formulations were fit to the Korsmeyer-Peppas kinetic release model and compared. Flux $(J)$ was calculated as $\mu \mathrm{g} / \mathrm{h} / \mathrm{cm}^{2}(28)$.

\section{RESULTS AND DISCUSSION}

\section{Identification of hederacoside C. by TLC}

The identification of the compound was done by three different types of solvents (mobile phase) to confirm presence of the marker, hederacoside $\mathrm{C}$. The $\mathrm{Rf}$ values of standard hederacoside $\mathrm{C}$ and the plant extract were observed in equal distance, as shown in Figure 1.

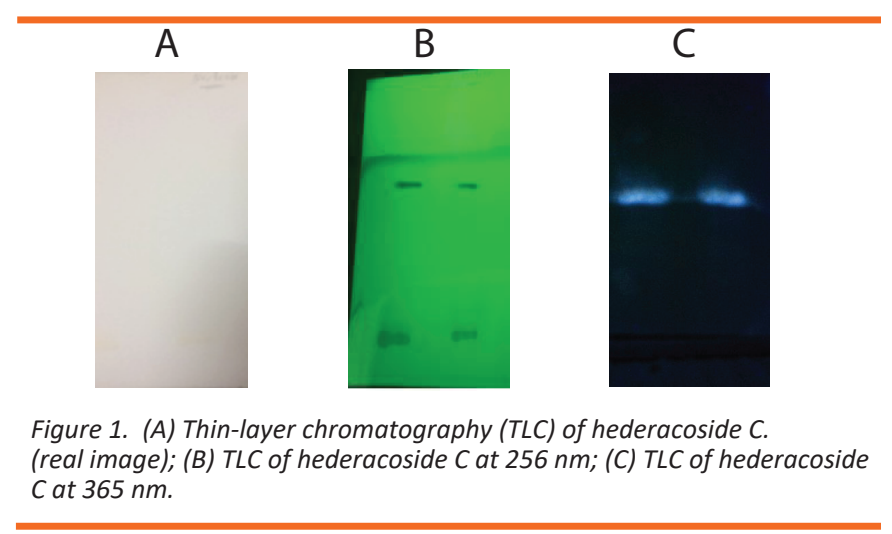

\section{Quantification of hederacoside C by HPLC}

The HPLC technique was used for the quantitative and qualitative analysis of hederacoside $\mathrm{C}$ from the plant extract and the formulations. The compound was confirmed with a retention time of $10.06 \mathrm{~min}$ for the standard and $9.66 \mathrm{~min}$ for the sample extract (Fig. 2). The hederacoside $\mathrm{C}$ content in the plant extract was $14.00 \%$, and the drug content in the microemulsion, gel, and ointment formulation was $99.10 \%, 98.23 \%$, and $97.45 \%$, respectively (Table 1 ).
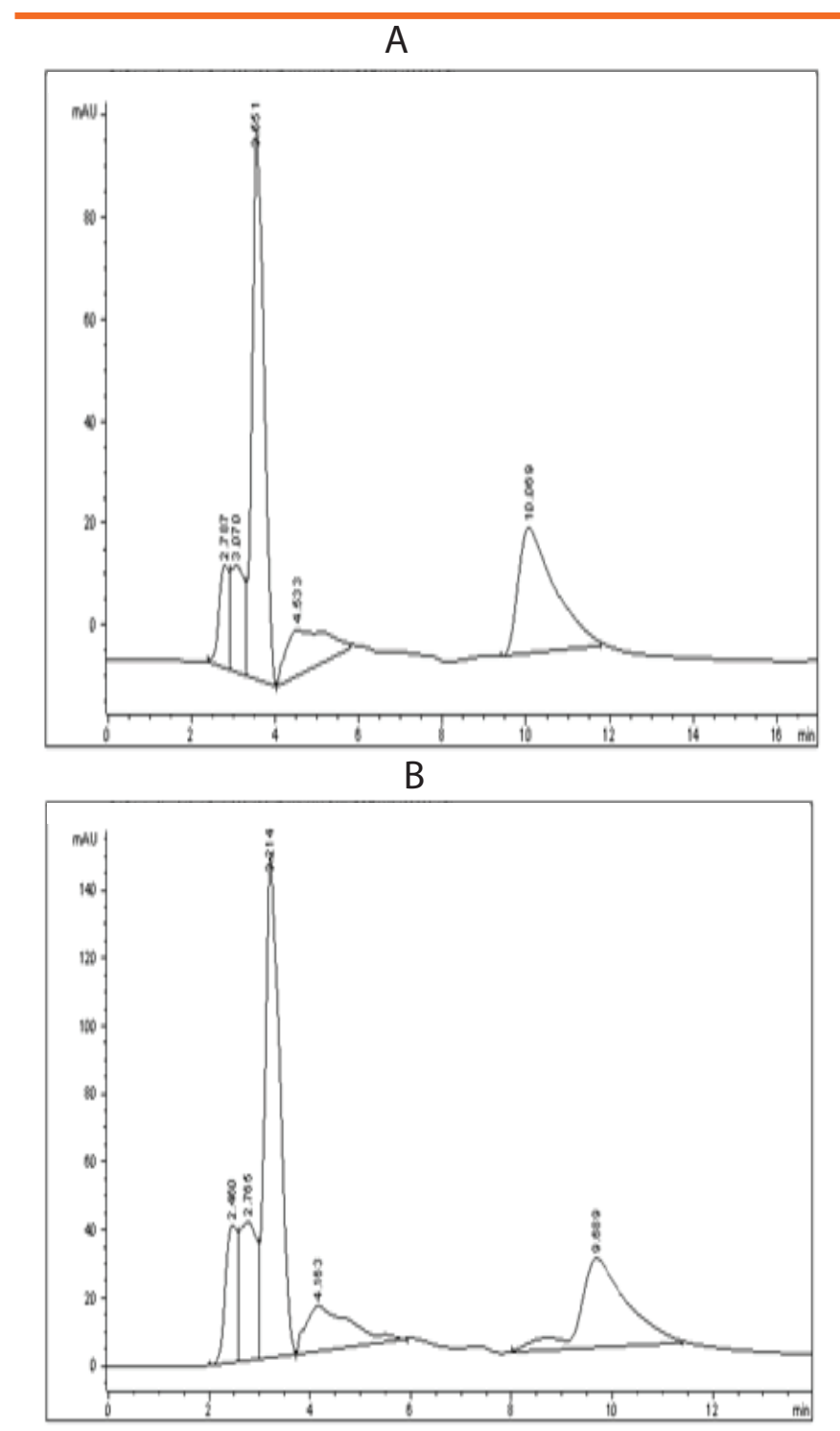

Figure 2. Chromatogram of (A) hederacoside $C$ (control retention time: $10.06 \mathrm{~min}$ ) and (B) isolated hederacoside C (retention time: $9.66 \mathrm{~min}$ ).

Table 1. Drug Content in Three Formulations Containing Hedera helix L. Extract

\begin{tabular}{|c|c|}
\hline Formulations & Drug Content \\
\hline Microemulsion & $99.10 \%$ \\
\hline Gel & $98.23 \%$ \\
\hline Ointment & $97.45 \%$ \\
\hline
\end{tabular}

\section{Comparison of $\boldsymbol{H}$. helix Formulations}

A 1-g sample of herbal topical formulations containing hederacoside $\mathrm{C}$ were analyzed via dialysis cellulose membrane and natural rabbit skin, as shown in Figure 
$3 A$ and $B$, respectively. The microemulsion and gel formulations showed visible release from the cellulose membrane and rabbit skin, and both formulations had similar release and permeability patterns at 6 h ( $f 2=68$ and 80 , respectively) and up to 24 h ( $f 2=60$ and 60 , respectively), as indicated in Table 2 . The ointment formulation did not have a similar release and permeability pattern as the dialysis membrane and rabbit skin. The $f 2$ value for the ointment was less than 50 when compared to the microemulsion and gel formulations. These data indicate that the membrane nature had a considerable impact on the release and permeability of the formulations.
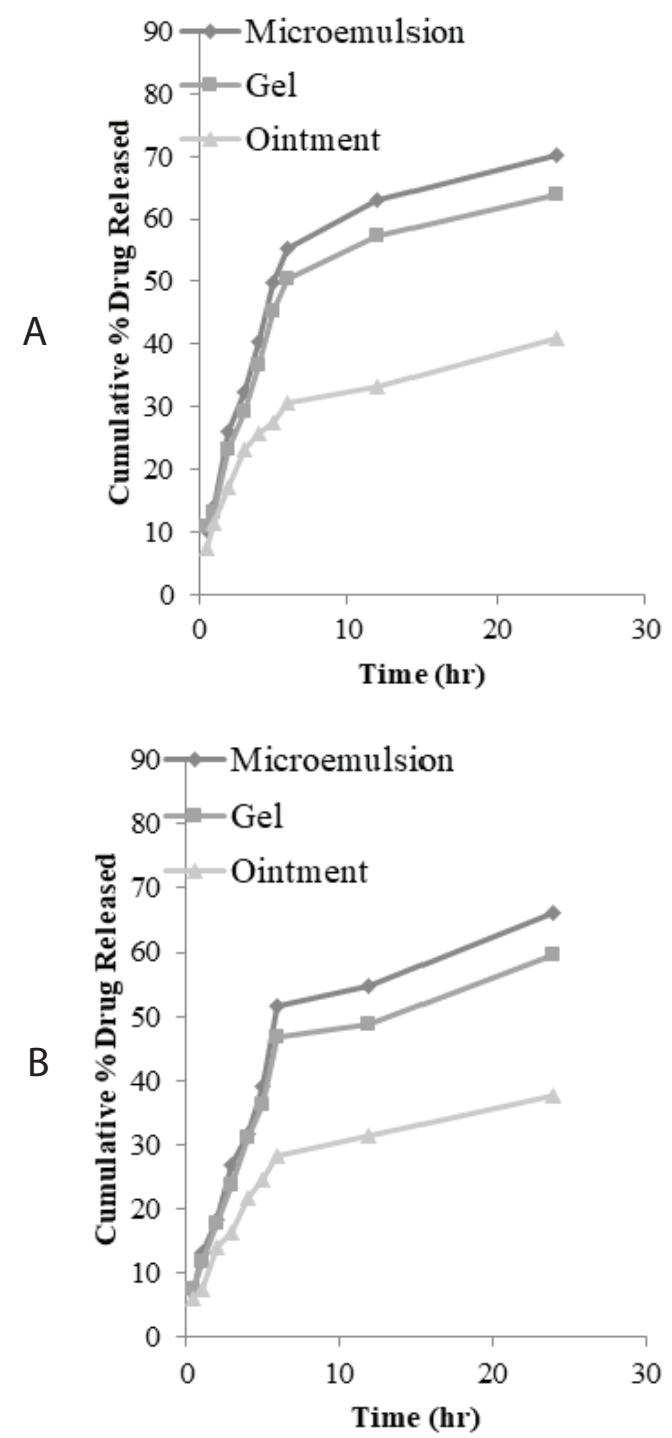

Figure 3. Comparison of mean drug release profiles of hederacoside $C$ from three formulations containing Hedera helix L. extract using (A) dialysis cellulose membrane and (B) natural rabbit skin.
Table 2. Similarity Factor (f2) Analysis of Three Formulations Containing Hedera helix $L$.

\begin{tabular}{|c|c|c|c|c|}
\hline \multirow{2}{*}{ Formulations } & \multicolumn{2}{|c|}{$\begin{array}{c}\text { Dialysis Cellulose } \\
\text { Membrane }\end{array}$} & \multicolumn{2}{c|}{ Natural Rabbit Skin } \\
\cline { 2 - 5 } & $\mathbf{0 - 6} \mathrm{h}$ & $\mathbf{0 - 2 4} \mathrm{h}$ & $\mathbf{0 - 6} \mathrm{h}$ & $\mathbf{0 - 2 4} \mathrm{h}$ \\
\hline Microemulsion vs. Gel & 68 & 60 & 80 & 60 \\
\hline $\begin{array}{c}\text { Microemulsion vs. } \\
\text { Ointment }\end{array}$ & 36 & 27 & 42 & 31 \\
\hline Gel vs. Ointment & 41 & 32 & 36 & 36 \\
\hline
\end{tabular}

The amount of drug released from the different formulations (microemulsion, gel, and ointment) using the dialysis cellulose membrane and natural rabbit skin are listed in Table 3 and 4, respectively. The amount of hederacoside $\mathrm{C}$ released from different formulations using the cellulose membrane and rabbit skin can be arranged according in descending order as microemulsion $>$ gel > ointment.

The similarity between both in vitro and ex vivo results illustrates the value of administrating hederacoside $C$ as a topical dosage form, as shown in Figure $2 \mathrm{~A}$ and $\mathrm{B}$. The release profiles for the microemulsion and gel were clear within $24 \mathrm{~h}$ (Tables 3 and 4). Although drug release from the microemulsion formulation through the cellulose membrane and rabbit skin was $70.239 \%$ and $66.0571 \%$ after $24 \mathrm{~h}$, respectively, the large amount of hederacoside $C$ released may be due to the presence of enhancers (i.e., polysorbate 80 and ethanol). The large release from the gel formulation may be due to olive oil and swell-up in the first hour, and its first burst may increase the penetration of drug and then drop. Drug release from the gel through the cellulose membrane and rabbit skin was $63.9157 \%$ and $59.5 \%$, respectively. The amount of drug released from the ointment through the cellulose membrane and rabbit skin was $40.9514 \%$ and $37.64 \%$, respectively. The slow release of the drug from the ointment may be due to affinity of the drug to the base and its viscosity. Furthermore, slow release from the ointment may be due to the absence of the oily phase in this formulation. The drug release through the cellulose membrane and rabbit skin follows the Korsmeyer-Peppas model. Table 5 shows the flux $(J)$ values for all dosage forms. The use of ethanol solvent as a receptor medium for the semisolid dosage form increases the rate of drug release between the donor and receptor compartments $(23,24)$. The penetration of hederacoside $C$ through the cellulose membrane was more than the rabbit skin, which could be explained by the above-mentioned reason or the rabbit skin used in this study was thicker or had smaller pore size than the cellulose membrane, which could not allow more drugs to 
Table 3. Hederacoside C Release from Three Formulations Using Dialysis Cellulose Membrane

\begin{tabular}{|c|c|c|c|c|c|c|c|c|c|c|}
\hline \multirow{2}{*}{$\begin{array}{c}\text { Amount } \\
\text { of Drug } \\
\text { Released } \\
\text { after } 24 \mathrm{~h}(\%)\end{array}$} & \multirow{2}{*}{ Base } & \multicolumn{9}{|c|}{ Amount of Drug Release at Each Time Point $\left(\mathrm{mg} / 1.5 \mathrm{~cm}^{2}\right)$} \\
\hline & & $0.5 \mathrm{~h}$ & $1 \mathrm{~h}$ & $2 \mathrm{~h}$ & $3 \mathrm{~h}$ & $4 \mathrm{~h}$ & $5 \mathrm{~h}$ & $6 \mathrm{~h}$ & $12 \mathrm{~h}$ & $24 \mathrm{~h}$ \\
\hline 70.239 & Microemulsion & 0.7320 & 0.9823 & 1.8291 & 2.2747 & 2.8186 & 3.4818 & 3.861 & 4.4177 & 4.9167 \\
\hline 63.9157 & Gel & 0.7575 & 0.9211 & 1.6325 & 2.0414 & 2.5765 & 3.1647 & 3.5348 & 4.0088 & 4.4741 \\
\hline 40.9514 & Ointment & 5.5276 & 0.8042 & 1.2057 & 1.6306 & 1.803 & 1.9204 & 2.1429 & 2.3259 & 2.8666 \\
\hline \multicolumn{11}{|c|}{$R^{2}$ (coefficient of correlation) } \\
\hline Formulations & \multicolumn{2}{|c|}{ Zero Order } & First Order & \multicolumn{2}{|c|}{ Higuchi } & $\begin{array}{l}\text { Hixon- } \\
\text { Crowell }\end{array}$ & \multicolumn{2}{|c|}{$\begin{array}{c}\text { Korsmeyer- } \\
\text { Peppas }\end{array}$} & \multicolumn{2}{|c|}{ Best-Fitting Model } \\
\hline Microemulsion & \multicolumn{2}{|l|}{0.8197} & 0.9636 & \multicolumn{2}{|c|}{0.9493} & 0.9644 & \multicolumn{2}{|c|}{0.9599} & \multicolumn{2}{|c|}{ Korsmeyer-Peppas } \\
\hline Gel & \multicolumn{2}{|l|}{0.8207} & 0.9466 & \multicolumn{2}{|c|}{0.9496} & 0.9651 & \multicolumn{2}{|c|}{0.8502} & \multicolumn{2}{|c|}{ Korsmeyer-Peppas } \\
\hline Ointment & 0.8131 & \multicolumn{2}{|c|}{0.8693} & \multicolumn{2}{|c|}{0.9512} & 0.9789 & \multicolumn{2}{|c|}{0.8502} & \multicolumn{2}{|c|}{ Korsmeyer-Peppas } \\
\hline
\end{tabular}

Table 4. Hederacoside C Release from Three Formulations Using Natural Rabbit Skin

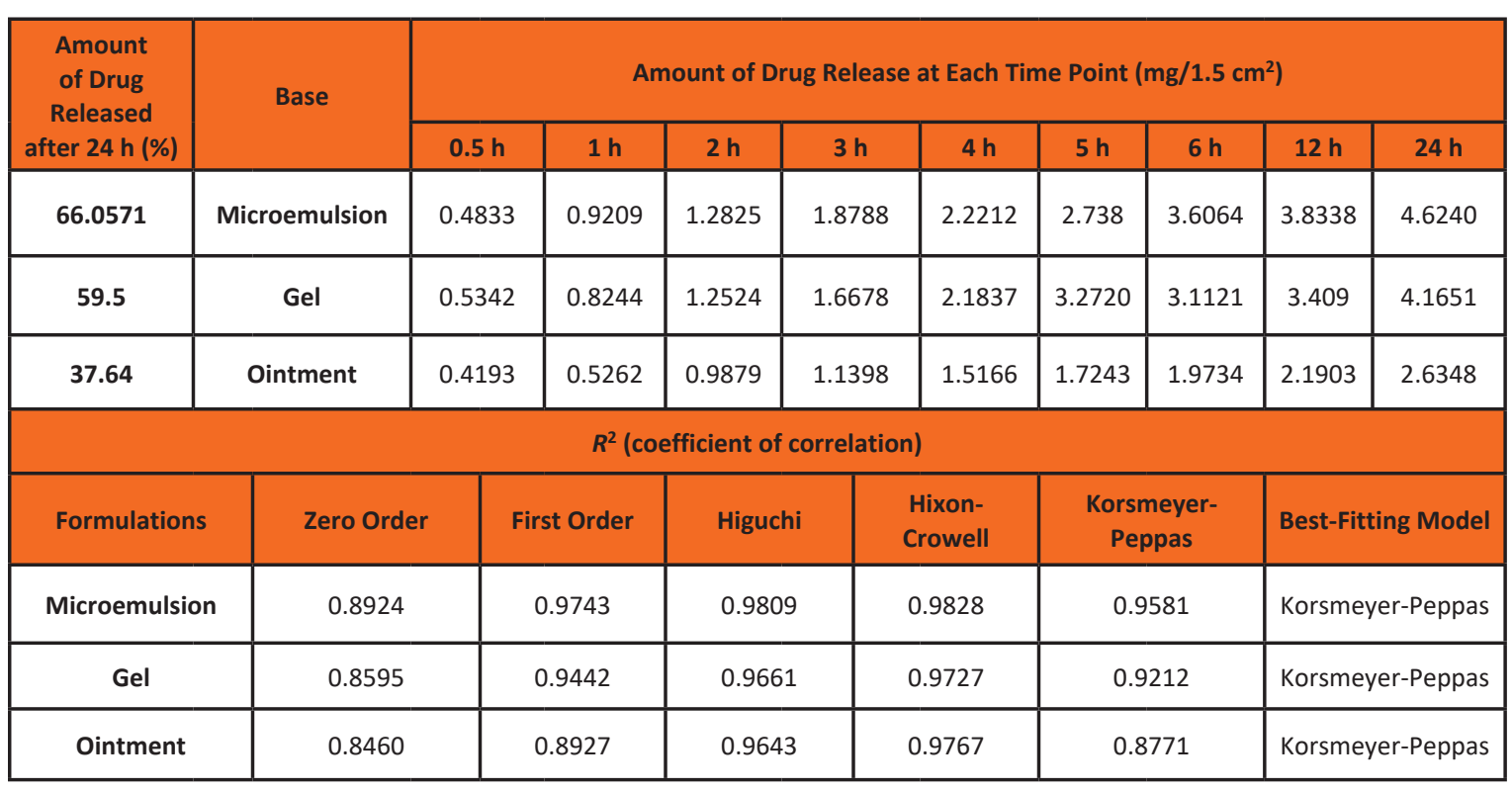

Table 5. Flux Values of Three Formulations Containing Hedera helix L. Extract

\begin{tabular}{|c|c|c|}
\hline Formulations & $\begin{array}{c}\text { Dialysis Cellulose Membrane } \\
\left(\mu \mathrm{g} / \mathrm{cm}^{2} / \mathrm{h}\right)\end{array}$ & $\begin{array}{c}\text { Natural Rabbit Skin } \\
\left(\mu \mathrm{g} / \mathrm{cm}^{2} / \mathrm{h}\right)\end{array}$ \\
\hline Microemulsion & 7.10 & 6.10 \\
\hline Gel & 5.02 & 4.12 \\
\hline Ointment & 3.80 & 2.40 \\
\hline
\end{tabular}


penetrate. Additional studies are required to determine if the experimental effects were only the result of pore size, enhancer, or if the behavior of the membrane material also contributed to the inequitable power.

\section{CONCLUSION}

The current study demonstrated that dialysis cellulose membrane, natural rabbit skin, and Franz diffusion cells can be used to assess release of hederacoside $C$ from microemulsion, gel, and ointment formulations containing $H$. helix extract. The in vitro and ex vivo release experiments showed similar release rates. The ointment showed a slower rate of drug release through dialysis cellulose membrane and natural rabbit skin. Statistical analysis proved that each parameter was significant with little variation. These formulations could be used for further studies, and in vitro and ex vivo diffusion cell experiments can be utilized to develop improved formulations of herbal medicines.

\section{ACKNOWLEDGEMENTS}

The authors would like to thank the Government of Balochistan Department of Health (for providing study leave), and Dr. Mahmood Ahmad; Dean and Faculty of Pharmacy at The Islamia University of Bahawalpur for support to complete this research work.

\section{CONFLICT OF INTEREST}

The authors discolsed no conflicts of interest related to this study.

\section{REFERENCES}

1. Stauss-Grabo, M.; Atiye, S.; Warnke, A.; Wedemeyer, R. S.; Donath, F.; Blume, H. H. Observational study on the tolerability and safety of film-coated tablets containing ivy extract (Prospan ${ }^{\circledR}$ Cough Tablets) in the treatment of colds accompanied by coughing. Phytomedicine, 2011, 18, 433-436. DOI: 10.1016/j. phymed.2010.11.009.

2. Cwientzek, U.; Ottillinger, B.; Arenberger, P. Acute bronchitis therapy with ivy leaves extracts in a two-arm study. A double-blind, randomised study vs. another ivy leaves extract. Phytomedicine, 2011, 18, 1105-1109. DOI:10.1016/j. phymed.2011.06.014.

3. Assessment report on Hedera helix L. folium. European Medicines Agency, Committee on Herbal Medicinal Products; European Medicines Agency: London, 2011.

4. Sieben, A.; Prenner, L.; Sorkalla, T.; Wolf, A.; Jakobs, D.; Runkel, F.; Häberlein, H. a-Hederin, but not hederacoside $C$ and hederagenin from Hedera helix, affects the binding behavior, dynamics, and regulation of b2-adrenergic receptors. Biochemistry 2009, 48, 3477-3482. DOI: 10.1021/bi802036b.

5. European Pharmacopoeia $8^{\text {th }}$ ed; European Directorate for the
Quality of Medicines \& Healthcare: Strasbourg, France, 2014, 1448-1449.

6. Gruenwald, J.; Brendler, T.; Jaenicke, C., Eds. PDR for Herbal Medicine; Medical Economic Company: Montvale, NJ, 2000; pp 284-285.

7. Blumenthal, M.; Busse, W. R.; Goldberg, A.; Gruenwald, J.; Hall, T.; Riggins, C. W.; et al. Eds.; The Complete German Commission E Monographs: Therapeutic Guide to Herbal Medicines; American Botanical Council: Austin, TX, 1998.

8. Anton, J. G.; Puche, J. C.; Valles, A. G.; Passerini, E.; Composition for the prevention and treatment of cellulitis. U.S. Patent 20070031516, February 8, 2007.

9. Wichtl, M., Ed. Herbal Drugs and Phytopharmaceuticals. A Handbook for Practice on a Scientific Basis 3rd ed.; Medpharm: Stuttgart, Germany, 2004, pp 274-277.

10. Gul, R.; Jan, U. S.; Ahmad, M.; Akhtar, M.; Faridullah, S. Use of traditional herbal medicines for the treatment of asthma in Balochistan. Curr. Res. J. Biol. Sci , 2017, 9, 16-22. DOI: 10.19026/ crjbs.9.5138.

11. Harborne, J. B. Phytochemical Methods. Chepman and Hall London: London, England, 1973, pp. 5-6, 33-88. DOI: 10.1007/978-9-009-5921-7..

12. Chen, H.; Chang, X.; Du, D.; Li, J.; Xu, H.; Yang, X. Nanoemulsionbased hydrogel formulation of ibuprofen for topical delivery. Int. J. Pharm. 2006, 315, 52-58. DOI: 10.1016/j.ijpharm.2006.02.015.

13. Gul, R.; Jan, U. S.; Ahmad, M.; Akhtar, M.; Faridullah, S. Formulation, characterization, in vitro and ex vivo release of Ephedra extract from topical preparations using dialysis membrane and rabbit skin. Dissolution Technol. 2017, 24, 24-30. DOI: 10.14227/DT240417P24.

14. Khiljee, S.; Rehman, N. U.; Sarfraz, M. K.; Montazeri, H.; Khiljee, T.; Löbenberg, R. In vitro release of Indian pennywort, walnut and turmeric from topical preparations using two different types of membranes. Dissolution Technol. 2010, 17, 27-32. DOI: 10.14227/DT170410P27.

15. Proniuk, S.; Dixon, S. E.; Blanchard, J. Investigation of the utility of an in vitro release test for optimizing semisolid dosage forms. Pharm. Dev. Technol. 2001, 6, 469-476. DOI: 10.1081/PDT100002255.

16. Marriott, J.F.; Wilson, K. A.; Langley, C. A.; Belcher, D. Pharmaceutical Compounding and Dispensing; Pharmaceutical Press: London. 2006; p 162.

17. Pellet, M.; Watkinson, A.; Brain, K.; Hadgraft, J. Synergism between super saturation and chemical enhancement in permeation of flurbiprofen through human skin. In Perspectives in Percutaneous Penetration; STS Publishing: Cardiff, 1997; pp 86-89.

18. Özgüney, I. S.; Karasulu, H.; Kantarei, G.; Sözer, S.; Güneri, T.; Ertan, G. Transdermal delivery of diclofenac sodium through rat skin from various formulations. AAPS PharmSciTech. 2006, 7, 39-45. DOI: 10.1208/pt070488.

19. Jain, G. K.; Sharma, A. K.; Agrawal, S. S. Transdermal controlled 
administration of verapamil enhancement of skin permeability. Int. J. Pharm. 1996, 130, 169-77. DOI: 10.1016/03785173(95)04222-9.

20. Murthy, S. N.; Hiremath, S. R. R. Physical and chemical permeation enhancers in transdermal delivery of terbutaline sulphate. AAPS PharmSciTech. 2001, 2, 1-5. DOI: 10.1208/pt0201_tn1.

21. Kim, J-H.; Choi, H-K. Effects of additives on the crystallization and the permeation of ketoprofen from adhesive matrix. Int. J. Pharm. 2002, 236, 81-85. DOI: 10.1016/S0378-5173(02)000170 .

22. Ueda, C. T.; Shah, V. P.; Derdzinski, K.; Ewing, G.; Flynn, G.; Maibach, H.; Marques, M.; Rytting, H.; Shaw, S.; Thakker, K.; Yacobi, A. Topical and transdermal drug products. Dissolution Technol. 2010, 17, 12-25. DOI: 10.14227/DT170410P12.

23. Shah, V. P.; Elkins, J. S.; Williams, R. L. Evaluation of the test system used for in vitro release of drugs for topical dermatological drug products. Pharm. Dev. Technol. 1999, 4, 377-385. DOI: 10.1081/ PDT-100101373.

24. Shah, V. P.; Maibach, H. I.; Jenner, J. Importance of In Vitro Drug Release. In Topical Drug Bioavailability, Bioequivalence, and Penetration; Springer: New York, 2014; pp 61-67. DOI: 10.1007/978-1-4939-1289-6_4.
25. Zhang, Y.; Huo, M.; Zhou, J. DDSolver: an add-in program for modeling and comparison of drug dissolution profiles. AAPS J. 2010, 12, 263-271. DOI: 10.1208/s12248-010-9185-1.

26. Yuksel, N.; Kanik, A. E.; Baykara, T. Comparison of in vitro dissolution profile by ANOVA-based, model-dependent and -independent methods. Int. J. Pharm. 2000, 209, 57-67. DOI: 10.1016/S0378-5173(00)00554-8.

27. Gohel, M. C.; Sarvaiya, K. G.; Mehta, N. R.; Soni, C. D.; Vyas, V. U.; Dave, R. K. Assessment of similarity factor using different weighting approaches. Dissolution Technol. 2005, 12, 22-27. DOI: 10.14227/DT120405P22.

28. Kreilgaard, M.; Pedersen, E. J.; Jaroszewski, J. W. NMR characterisation and transdermal drug delivery potential of microemulsion system. J. Control. Release. 2000, 69, 421-433. DOI: 10.1016/S0168-3659(00)00325-4. 